DOI: http://dx.doi.org/10.11565/arsmed.v38i1.80

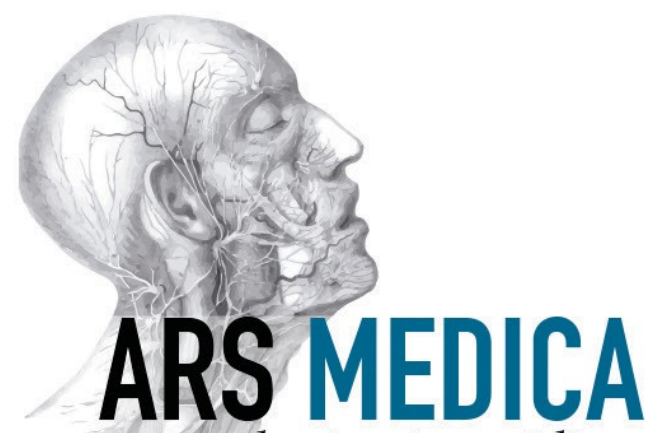

revista de ciencias médicas

Volúmen 38, número 1, año 2009

El presente artículo corresponde a un archivo originalmente publicado en Ars Medica, revista de estudios médicos humanísticos, actualmente incluido en el historial de Ars Medica Revista de ciencias médicas. El contenido del presente artículo, no necesariamente representa la actual línea editorial. Para mayor información visitar el siguiente vínculo: http://www.arsmedica.cl/index.php/MED/about/submissions\#authorGuidelines 


\section{El aborto terapéutico: un nuevo intento de despenalizar el aborto en el Derecho chileno}

Ángela Vinanco Martínez ${ }^{1}$

Profesora de Derecho Constitucional y de Bioética

Facultad de Derecho

Pontificia Universidad Católica de Chile

En nuestro país recientemente se han presentado dos mociones parlamentarias destinadas a la legalización del llamado "aborto terapéutico", concepto difuso y equívoco. Se analiza esta posibilidad legislativa a la luz de la doctrina y la normativa constitucional chilena que protege expresamente la vida del que está por nacer, procurando distinguir aquellas figuras de interrupción del embarazo validadas por el Derecho de las que constituyen aborto provocado, reconociendo que la despenalización de una forma de estas últimas es, necesariamente, admitir el aborto en Chile.

palabras clave: aborto, interrupción del embarazo; derecho a la vida; persona humana; nasciturus; conflicto de derechos.

\section{THERAPEUTIC ABORTION: A NEW ATTEMPT TO DECRIMINALIZE ABORTION IN CHILEAN LAW}

Two parliamentary motions have recently been introduced to discuss the legalization of so-called "therapeutic abortion", an ambiguous and equivocal concept. The goal is to analyze this possible legal reform under legal doctrine and the Chilean constitution, which expressly protects the life of the fetus, trying to distinguish all forms of pregnancy termination that are allowed by Chilean law, versus others that are induced and not permitted, recognizing that the decriminalization of the latter will necessarily lead to allowing abortion in Chile.

Key words: abortion, abortion decriminalization; termination of pregnancy; right to life; human being; nasciturus; conflicts between rights.

\section{Introducción}

El 19 de marzo de $2009^{2}$ los diputados señores De Urresti, Escobar, Espinosa,Farías, Jiménez, Monsalve, Núñez, Quintana, Rossi y Sule presentaron en la H. Cámara de Diputados el Proyecto de Ley contenido en el Boletín No 6420-11 titulado "Modifica el artículo 119 del Código Sanitario para permitir la interrupción médica del embarazo en caso de riesgo de la madre", el cual, citando algunas normas nacionales y comparadas, propone escuetamente reemplazar el texto del artículo 119 del actual Código Sanitario, por el siguiente: "Sólo con fines terapéuticos 
se podrá interrumpir un embarazo. Para proceder a esta intervención se requerirá la opinión documentada de dos médicos cirujanos".

La modificación propuesta no es más que reflotar la redacción original del artículo 119 del Código Sanitario, antes de su reforma en 1989, como veremos.

Por su parte, el 13 de mayo de 2009 el Senador Camilo Escalona presentó en el H. Senado de la República el Proyecto de Ley contenido en el Boletín No 652211 titulado Sobre interrupción terapéutica del embarazo, el cual considera entre sus fundamentos textualmente a los siguientes:

... Creemos que el estado de la ciencia médica permite afirmar que la vida humana comienza con el feto, cuyos derechos se encuentran suspendidos de gocey ejercicio hasta su nacimiento, no dependiendo de la acción de un tercero que dicho acontecimiento suceda. La inviolabilidad del derecho a la vida, incluyendola del que se presume nacerá, es el antecedente que habilita el repudio penal de la interrupción injustificada del embarazo ${ }^{3}$.

Una interpretación armónica de los instrumentos internacionales sobre protección de derechos exige que la materialización del derecho de la mujer a Vivir una Vida Libre de Violencia, importe necesariamente el respeto a su vida y, en consecuencia, a no ser obligada a la continuación de un embarazo que la pone en peligro inminente.

...Resulta moralmente inaceptable que no abordemos el dilema ético que debeenfrentar la madre y el o los profesionales que la asisten durante el embarazo, cuando la continuación del mismo pone en peligro su vida. Esta cuestión no puedequedar entregada a una resolución fáctica al margen del derecho. Esta colisión de intereses morales legítimos exige normar sobre la interrupción del embarazo cuando la vida de la madre está en peligro.

La derogación del artículo 119 del Código Sanitario 4 que permitía la interrupción terapéutica del embarazo importa condenar, sin mediar debate ni discusión ala luz de la ciencia médica, la razón y las aspiraciones morales de una sociedad, cualquier interrupción del embarazo que no sea natural ${ }^{5}$.

...Deja en el desamparo la regulación que corresponde al derecho hacerse cargo,como es la colisión entre el Derecho a la Vida de la madre y los derechos del no nato, cuando la vida de la primera está en peligro; también deja sin ponderación la cuestión de la viabilidad del feto in útero o ex útero, esto es, cuando, sin mediarpeligro inminente para la vida de la madre existe la certeza de la inviabilidad del feto, o bien cuando existe razonable certeza de que el no nato ha muerto y el mantenimiento en el útero materno sólo provocará de modo inexorable la muerte de la madre, sólo por mencionar aquellas cuestiones que deben ser decididas, al margen del derecho, en forma cotidiana. 
...Es en este contexto, donde es preciso que las decisiones que se adoptan cotidianamente en los hospitales y clínicas de nuestra nación estén amparados por el derecho, estableciendo la interrupción terapéutica del embarazo, aquella destinada a resolver favor Mater la colisión entre los derechos del no nato y el peligro a la vida de la madre que el embarazo puede ocasionar...

En virtud de las fundamentaciones transcritas, el Proyecto propone reemplazarel artículo 119 del Código Sanitario por el siguiente: “Art. 119. Se podrá interrumpirel embarazo, sólo con fines terapéuticos, mediante intervención médica, cuando ésta sea documentada por dos médicos cirujanos."

Como lo expondremos a lo largo del presente trabajo, el concepto de "fines terapéuticos" que ambos proyectos utilizan, dado su contexto y fundamentación, abarca una variada serie de situaciones jurídica y éticamente diversas que deben ser suficientemente clarificadas, pues revisten connotaciones de relevancia para el derecho a la vida ${ }^{6}$, la protección del no nacido, la salvaguarda de la salud materna y la relación armoniosa entre los derechos de las personas. Del mismo modo, uno de ellos conlleva la idea de revivir una norma cuya aplicación en Chile tuvo una variada gama de aplicaciones, varias de ellas incompatibles con nuestra Constitucióny con los tratados internacionales suscritos y ratificados por Chile.

\section{Qué es el aborto}

\section{Concepto de "Aborto"}

No existe duda alguna acerca de la punibilidad del aborto en Chile, tantoen referencia a la norma vigente del artículo 119 del Código Sanitario ya citada, como al precepto del Código Penal que castiga al que "maliciosamente causare un aborto" (artículo 342). Sin embargo, el concepto de aborto ha tenido que ser definido más bien jurisprudencialmente, ya que ni la ley ni la propia Constitución, al específicamente proteger la vida del que está por nacer, han definido qué ha de entenderse por aborto. Sobre la base de esa realidad, es interesante atender a los fallos de nuestros tribunales, que han señalado en casos como el caratulado Contra Inés Riquelme Riquelme y $\operatorname{Otros}^{7}$ que si bien "el Código Penal no define el aborto, y aunque el empleo de dicho término está ligado a la idea de separación del feto de la madre, en opinión de muchos tratadistas de Derecho Penal y de Medicina Legal, tiene un alcance más amplio, cual es el de comprender "toda maniobra destinada a interrumpir el embarazo impidiendo que él llegue a su término natural, cual es el nacimiento del producto de la concepción”. En esa perspectiva, es irrelevante que el feto se haya desprendido o no del cuerpo de la madre, siendo lo esencial que se le haya privado de la vida, dentro o fuera del vientre materno: esto coincide con el sentido natural y obvio que en el uso general tiene la expresión "aborto" . Mismo punto de vista se manifiesta en Contra Teresa Riveros y Otras 9 .

Si agregamos las características anteriores a la construcción de tipos delCódigo Penal, queda en evidencia que el aborto como figura punible se compone de al menos tres características fundamentales:

a) Una maniobra o acción ejecutada por el autor, lo que da cuenta de una conducta activa ${ }^{10}$. 
b) Esta conducta tiene por fin evitar que el embarazo continúe.

c) Con el propósito de evitar el nacimiento del niño en gestación, lo que ha de entenderse como un ánimo o intención destructiva y matadora.

La idea fundamental en el aborto es la protección del bien jurídico vida respectodel sujeto en gestación, lo que importa la equiparación del nasciturus -desde el momento de la concepción hasta su nacimiento- con el ser ya nacido ("El embrión es reconocido en nuestro ordenamiento jurídico como una persona" ${ }^{11}$ ). Si se estimaque no corresponde diferenciar uno y otro, implícitamente se estaría aceptando, a suvez, que el nacimiento del ser humano carecería de trascendencia jurídico-penal ${ }^{12}$,ya que la calidad de persona referiría a la pertenencia a la especie humana y no al grado de desarrollo de un sujeto particular y menos al hecho de nacer, que revestiríaimportancia sólo en la esfera de la protección pero no en el distingo respecto de la tutela del derecho a la vida.

De este modo, el delito de aborto comparte la naturaleza del delito de homicidio, pues implica directamente un atentado contra la vida humana y el especial disvalor de desconocer la dignidad y el respeto que esa vida merece ${ }^{13}$.

\section{La protección de la vida del que está por nacer en la Carta de 1980 y la exclusión constitucional del aborto}

El signo más profundo y fundamental de la Constitución chilena actual, en esta materia, reside en la tríada persona -igualdad-protección de la vida y la de la integridad del sujeto.

En efecto, el artículo $1^{\circ}$ de la Carta, al expresar en su inciso $1^{\circ}$ que "Las personas nacen libres e iguales en dignidad y derechos" 14 , estableció como una de las claves de nuestro ordenamiento supremo la consideración por la persona humana asociada con su pertenencia a la especie y, por tal, con igual dignidad y derechos que todas las demás. Tal consideración no depende de su grado de desarrollo,salud, viabilidad u otros atributos y se ha manifestado en repetidas oportunidades a propósito de la dictación de leyes complementarias ${ }^{15}$ y como asimismo lo ha reconocido nuestra justicia constitucional ${ }^{16}$ :

...el derecho a la vida asegurado por el artículo $19 \mathrm{~N}^{\circ} 1$ de la Constitución, en consonancia con el artículo $3^{\circ}$ de la Declaración Universal de los Derechos Humanos; el artículo 6.1 del Pacto Internacional de Derechos Civiles y Políticos; el artículo $1^{\circ}$ de la Declaración Americana de los Derechos y Deberes del Hombre,y el artículo $4^{\circ}$ de la Convención Americana de Derechos Humanos, asegura a toda persona -incluyendo al nasciturus - el derecho a mantener la vida y a conservarla frente a los demás hombres. Si se quiere, "es el derecho a que nadie nos la quite, y a que no pueda suprimirla ni cercenarla su propio sujeto" (José JoaquínUgarte Godoy. El derecho a la vida y la Constitución. Revista Chilena de Derecho,Volumen 33, N 33, 2006, pág. 514)... (Considerando 56). 
... por su parte, la jurisprudencia de nuestros tribunales también se ha pronunciado en torno a la protección de la "persona" que está por nacer, en cuanto sujeto de derecho, en forma congruente con la preceptiva constitucional. Así, en fallo de la Corte Suprema, de 30 de agosto de 2001, se señaló que: el que está por nacer cualquiera sea la etapa de su desarrollo pre natal, pues la norma constitucional no distingue, tiene derecho a la vida, es decir, tiene derecho a nacer y a constituirse en persona con todos los atributos que el ordenamiento jurídico le reconoce, sin que a su respecto opere ninguna discriminación (considerando17으) (Considerando 59).

Tal consideración por la persona humana generó, en la reflexión constitucional de la época, la idea que ello debía compatibilizarse con un reconocimiento efectivo al derecho a la vida: "este derecho o garantía debe ser necesariamente destacado en la actualidad, ya que, desde hace algún tiempo, la vida humanaha sido menospreciada, que se han cometido diversos y deleznables delitos que atentan contra ella. Considera que debe contemplarse el derecho a la vida junto con el derecho a la integridad física, porque en definitiva lo que hay que asegurares una vida realmente humana"17.

La introducción de la garantía del derecho a la vida en la Constitución de 1980generó interesantes debates en las Actas de la Comisión de Estudios de la Nueva Constitución, que demuestran las perspectivas con las que los comisionados veían tal tema fundamental y sus implicancias sobre la penalización del aborto.

En efecto, la unanimidad de los miembros de la Comisión y los profesores invitados coincidieron en que debía consagrarse constitucionalmente el derecho a la vida, acordándose finalmente en Sesión No 89 de 21 de noviembre de 1974, y se debatió si debía establecerse en forma escueta o desarrollarlo en lo referente a la protección de la vida del que está por nacer, introduciendo alguna disposición relativa al aborto; quedando proscrito en todas sus formas o estableciendo unanorma más flexible ${ }^{18}$. Como no hubo total acuerdo sobre esta materia, pues algunoscomisionados consideraban procedente el llamado "aborto terapéutico" o el aborto en caso de violación, se optó entonces por establecer sólo la regla de protección similar al Código Civil en la Constitución.

Sin embargo, tal discusión de modo alguno puede estimarse como una validación del aborto por quienes primero estudiaron la Constitución actual, puesla totalidad del contexto y de los valores citados a propósito de la creación de laCarta de 1980 son meridianamente claros en cuanto a que para la Constitución la vida es tan valiosa, defendible y digna, cuando se trata de una criatura engestación como cuando estamos en presencia de un ser humano ya nacido, y si bien los comisionados esgrimieron opiniones diversas respecto de las situacionesexcepcionales cuya despenalización podía considerarse posible, jamás estimaroncomo una instancia legal la figura del aborto y menos que el niño por nacer nofuera digno de protección constitucional en términos amplios y equiparables al nacido ${ }^{19}$, como además lo ha venido reiterando el intérprete constitucional en lajurisprudencia antes citada. 


\section{La situación de Chile ante sus compromisos internacionales en relación con la figura del aborto}

Si bien Chile es signatario y ha ratificado la Convención sobre la Eliminación de Todas las Formas de Discriminación contra la Mujer (CEDAW), "el país no tieneun cuerpo legal que trate directamente los derechos sexuales y reproductivos, y la normativa existente se refiere a la defensa de los derechos del que está por nacer, la penalización del aborto y protección de la maternidad"20.

Sin embargo, ello no ha representado, en lo que al aborto respecta, un incumplimiento de compromisos internacionales por parte de nuestro país ${ }^{21}$. En efecto,si bien Chile firmó el protocolo facultativo del CEDAW con fecha 10 de diciembrede 1999, no lo ha ratificado hasta ahora, y ello se ha debido fundamentalmente ala estimación que se ha hecho en torno a que sería un instrumento que pugnaría por la despenalización del aborto en Chile, habida consideración que, si bien no establece nuevos derechos, es un medio para interpretar aquellos enunciados en laConvención y detallar las medidas que deberían ser adoptadas para implementartales derechos en situaciones específicas, medidas que pueden incluir remediospara mujeres individuales, por ejemplo compensación, o medidas sistémicas,tales como reformar la legislación, adoptar un cierto tipo de política o brindar servicios particulares. El protocolo incluye un procedimiento de comunicaciones, a través del cual el Comité examina las comunicaciones o quejas presentadas por"personas o grupos de personas" que aleguen ser "víctimas de una violación" a los derechos enunciados en la CEDAW y un procedimiento de investigación, por medio del cual el Comité inicia una investigación de violaciones "graves o sistemáticas"22.

Esta postura, por cierto, es plenamente compatible con lo previsto en el Pacto de San José de Costa Rica, ratificado por Chile, en su Artículo 4", inciso 1": "El Derecho a la Vida: Toda persona tiene derecho a que se respete su vida. Este derechoestará protegido por la ley y, en general, a partir del momento de la concepción. Nadie puede ser privado de la vida arbitrariamente.

\section{El "aborto terapéutico"}

\section{Un concepto difuso y equívoco}

La doctrina y la legislación comparada aportan numerosas definiciones de lo que ha de entenderse por aborto terapéutico:

a) "En el aborto terapéutico se trata de terminar con el embarazo y, con ello, con la vida del no nacido para preservar la vida de la madre. Se invocan aquí razones preventivas y curativas. Serían preventivas si se considerara que la gestación podría agravar o empeorar el pronóstico de una enfermedad de base; curativas cuando se considera que el embarazo está causando un peligro para la vida de la madre"23.

b) "El aborto terapéutico denomina a situaciones en las cuales entra enconflicto la salud de la madre con la vida del feto, de forma tal que para proteger aquélla se requiere lesionar la vida de éste" 24 . 
c) “La expresión 'aborto terapéutico'alude a dosrealidadescuyo significadoes totalmente diferente: por un lado puede significar 'matar a la criatura como medio para lograr un buen fin (curativo)', pero también puedesignificar 'realizar un procedimiento donde la muerte de la criatura no es el medio para curar, pero puede sobrevenir como consecuencia no deseada" 25 .

d) "Es aquella interrupción voluntaria de un embarazo antes de la viabilidadfetal por razones de salud materna" 26 .

e) "Es la interrupción del embarazo antes de las 20 semanas, por indicaciónmédica, debido a patologías maternas que son agravadas por el embarazo,por patologías maternas que repercuten negativamente sobre el crecimientoy desarrollo fetal y comprometen la vida del binomio madre-hijo"27.

f) “Estrictamente hablando, el aborto terapéutico es el que se practicacuando el embarazo está poniendo en grave peligro la vida o la salud de la madre gestante" 28 .

g) “En sentido estricto se ha llamado 'aborto terapéutico' a la interrupción del embarazo cuando el feto no es viable, o a la muerte provocada de un ser humano in utero porque ese embarazo o ese ser humano comprometegravemente la vida de la madre, y de no proceder en esta forma moriría la madre con ese humano en gestación y, en algunos casos, los mellizos o gemelos acompañantes"29.

h) 'Se habla aquí del 'aborto terapéutico' -entendido como la 'interrupción del embarazo' o ejecución de un aborto directo, realizada por agentes sanitarios competentes, con la finalidad de suprimir en la madre los riesgosreales o supuestos, provocados por la existencia del embarazo, el cual se fundamenta en dos argumentos básicos: a) La vida de la madre es de mayorcalidad que la vida del feto, pues ha adquirido mayor desarrollo y, por lotanto, dicha vida es más humana; b) la madre tiene el deber irrenunciable de conservar su vida, y si no cumple con éste deber está violando la leynatural”30 .

i) “El aborto terapéutico consiste en la destrucción y expulsión del feto con la específica finalidad de salvar la vida de la madre o evitar graves riesgos para la salud"31.

De estas definiciones se coligen diversos elementos utilizados en torno a la conceptualización de la figura del aborto terapéutico:

i. Preservación de la vida de la madre ante un riesgo actual o probable por agravamiento de una enfermedad.

ii. Conflicto de la salud de la madre con la del feto.

iii. Muerte de la criatura con el objeto de salvar a la madre.

iv. Término del embarazo antes de la viabilidad fetal por razones de salud materna.

v. Interrupción del embarazo a causa de patologías que comprometen la vida del binomio madre-hijo.

vi. Feto no viable.

vii. Suprimir en la madre los riesgos reales o supuestos, provocados por la existencia del embarazo. viii. Evitar graves riesgos para la salud. 
Como es obvio, varios de los elementos mencionados no pueden considerarsede una misma entidad, naturaleza o tratamiento, y ello es lo que explica la razón de la tremenda confusión y falta de claridad conceptual que se produce en la discusiónsobre esta materia. En efecto, algunos refieren a la madre, otros al hijo, otros a ambos; del mismo modo, se alude a la afectación de la vida, al grave riesgo para la salud, al deterioro de la salud o aun la pura inviabilidad del feto, sin siquiera clarificar si por salud entenderemos la definición de la OMS u otra ${ }^{32}$ y, a mayor abundamiento, se habla de la destrucción del feto, de su muerte o de la interrupción del embarazo como si fueran lo mismo.

Persona y Bioética, Universidad de La Sabana, Colombia, Vol. 9 n. 25 (2005) pág. 88-100.

Lo que no puede discutirse es lo paradojal y equívoco del término utilizado, pues relacionar la existencia de una terapia con un aborto provocado importa asociar términos esencialmente contrapuestos: "La expresión aborto terapéutico es equívoca y se presta a confusiones. Si se entiende por aborto terapéutico la muerte del embrión o feto como consecuencia indirecta de una acción médica sobre la madre, éste sería legítimo, siempre y cuando se den las condiciones requeridas. Si se entiende por aborto terapéutico la eliminación directa de la vida del embrión o del feto por razones eugenésicas, psicológicas o sociales, se trata de una acción ilegítima desde el punto de vista ético, y la cual, desde el punto de vista jurídico-social, reviste las características de un homicidio, sea éste de hecho, penado o no por la ley civil, en un lugar y una época histórica concreta" 33 .

De este modo, en las diversas conceptualizaciones sobre aborto terapéuticosubyacen conductas y justificaciones que se distinguen entre sí al punto de ser unas equiparables al homicidio como un directo atentado contra la vida y otras validadas por el Derecho y la ética sin necesidad de recurrir a modificación legislativa alguna ${ }^{34}$.

Incluso más, la doctrina se refiere con la mayor propiedad a aborto terapéuticoen casos de aborto provocado de fetos anencefálicos, lo cual constituye en realidadun aborto eugenésico en la mayoría de los casos: "En el ámbito de la legislación penal argentina no existe duda a mi juicio que una posible interrupción del embarazo en el caso de la anencefalia, en atención de las serias complicaciones que se presentan, particularmente para la mujer embarazada durante el último trimestre de la gestación, y frente a un cuadro de grave afectación de su salud psíquica y emocional, se encuadra en la figura del aborto terapéutico -que, según entiende la moderna doctrina penal, consagra una causal de justificación y no una simple exclusión de punibilidadcontemplado en el artículo 86 inc. $1^{\text {ro }}$ del Código Penal, a su vez en relación con el estado de necesidad justificante del art. 34 inc. $3^{\text {ro }}$ del mismo Código"35. Tal interpretación guarda relación con uno de los fundamentos del Proyecto del Senador Escalona, el cual considera como elemento a estimar precisamente "la cuestión de la viabilidad del feto in útero o ex útero, esto es,cuando, sin mediar peligro inminente para la vida de la madre, existe la certeza de la inviabilidad del feto.

\section{Conflicto de derechos y "aborto terapéutico"}


Una de las tesis que constituyen un auténtico trasfondo de la pretensión de validar la figura del aborto terapéutico consiste en la estimación que los derechos fundamentales se encuentran en una especie de pugna permanente que ha de ser resuelta optando por uno de ellos: "Al ejercer un derecho fundamental éste se puedeencontrar enfrente, en postura disconforme a la de ese ejercicio con el titular de otro derecho fundamental que pretende igualmente ejercerlo. En caso de conflicto o de antinomia subjetiva, si se permite la paradoja, quien debe ceder y quien debe continuar cómo se construye ese límite al derecho fundamental, son preguntas clavepara una teoría de los derechos fundamentales"36.

Según las posturas conflictivistas, los derechos fundamentales son realidades jurídicas que de modo natural tienden a colisionar, entendiéndose por "conflicto de derechos" "la inevitable colisión de derechos o de bienes jurídicos"37, lo cual lleva a aceptar que los conflictos se hacen inevitables. Frente a una situación de conflicto la solución se reduce sólo a preferir un derecho y desplazar el otro, es decir, poner a uno de los derechos en conflicto por encima del otro. Para esto se hacenecesario encontrar los mecanismos que justifiquen la preferencia de un derecho en detrimento del otro ${ }^{38}$.

\section{b) El derecho a la vida del nasciturus como "derecho cenicienta"39}

Como en el caso del aborto terapéutico se contrapone un mismo derecho (vida) o dos (vida y salud) pero respecto de titulares distintos, esto es, madre e hijo, la forma de solucionar tal pugna es determinar a priori quién tiene mejorderecho y por qué. Tal solución puede ser hasta cierto punto sencilla si el propio ordenamiento prioriza a un individuo sobre otro o despoja a uno de los miembros del binomio de la calidad de persona: "(los embriones) no son personas ni la protección de su vida representa un interés comparable al derecho a la vida...(esta) opción corresponde al punto de vista del derecho constitucional federal norteamericano, conforme a la jurisprudencia de la Corte Suprema federal. Segúneste tribunal, la vida de los seres humanos antes de su nacimiento puede representar un legítimo interés estatal (legal), pero no tiene el carácter de un interésde relevancia constitucional ${ }^{40}$.

Este descenso radical del estatus del nasciturus ante el eventual conflicto permite resolver este último mediante un proceso de jerarquización de su derecho en la medida de considerar que, por tenerlo a él de titular, pasa a ser simplemente un interés o un derecho de segundo orden: "En lo que sigue, se partirá de que, en sentido estricto, es enemigo para el Derecho penal aquel ser humano, y sólo aquel ser humano, al que, en la medida en que se le considere fuente de malestar para quienes tienen el poder jurídico de definición, se le niega toda protección penal (y aun jurídica). Dicha denegación de protección tiene lugar mediante su definición como nopersona en absoluto. En este sentido estricto es no-persona para el Derecho penal aquel ser humano, y sólo aquel ser humano, cuyo sustrato antropológico se deconstruye jurídica y/o filosóficamente, siendo reconstruido como un ente perteneciente al Derecho de cosas. Como se observa, aquí sí se produce una radical coincidencia entre la condición de enemigo y la de nopersona. El enemigo es definido como no-persona; es, por definición, el "otro" a quien se excluye. Es decir, aquel sujeto cuyos bienes, si son en cierto modo protegidos, desde luego no es por una razón de principio, esto es, porque sean suyos, sino por alguna razón pragmática, 
perfectamente susceptible de ser modificada. Básicamente, por uninterés (coyuntural) colectivo o de ciertos terceros" ${ }^{\prime 1}$.

La problemática de este tipo de soluciones es que a menudo generan no sólo desmedro de derechos sino exclusión de sus titulares de la protección jurídica:“Concebir los derechos fundamentales como realidades contrapuestas entre síque tienden a entrar en colisión, la cual se resuelve a través de mecanismos que jerarquizan derechos (en abstracto o en concreto), trae como consecuencia la existencia de una suerte de derechos de primera categoría y otros de segunda. Esto significará que cuando un derecho de segunda tiene la desdicha de cruzarse con uno de primera queda desplazado, sacrificado, afectado en su contenido jurídico, en buena cuenta, vulnerado. De esta manera, mediante posiciones conflictivistas de los derechos fundamentales, se pretende dar cobertura y legitimar situaciones que, dependiendo de las circunstancias de cada caso, pueden llegar a configurar verdaderas vulneraciones al contenido constitucional de los derechos" $"$.

Por esta causa, la introducción del aborto terapéutico como figura legal no representa una postura excepcional ante la protección del derecho a la vida del nasciturus sino la aceptación de una jerarquización que ubica en un plano secundario a su derecho y que necesariamente trasunta hacia el ordenamiento jurídico general: "Por ejemplo, una norma que prohibe el aborto y otra que permite el abortoterapéutico se hallan en una posición de conflicto abstracto, pues la especie de los abortos terapéuticos forma parte del género de los abortos; en consecuencia, o una de las normas no es válida o la segunda opera siempre como regla especial, es decir,como excepción constante a la primera. Podemos constatar la antinomia y adelantarsu solución sin necesidad de hallarnos en presencia de un caso concreto"43.

\section{c) "Aborto terapéutico" y conflicto de derechos}

\section{c.1. El nasciturus y el conflicto aparente o real de su derecho a la vida con otros derechos}

La despenalización de cualquier tipo de aborto pone al legislador en la situación de determinar si hay situaciones que, de suyo, autoricen a realizar conductas expresamente destinadas a la destrucción del embrión implantado. Tal determinación, si analizamos lo ya expresado, importa una decisión del legislador acerca de la preeminencia del derecho invocado en asociación con la causal, por sobre el derecho a la vida del nasciturus, o bien, ignorando incluso el eventual conflicto, declarando que el nasciturus no tiene derecho alguno sino un interés o una expectativa que cede ante el derecho invocado.

No es efectivo, como se pretende a veces en el debate legislativo, considerar que el derecho a la vida del nasciturus puede permanecer indemne pese a la legalización de algún tipo de aborto. Reconocer el aborto como legal significa a la par desconocer el derecho afectado y las razones o jerarquizaciones podrán ser muchas o pocas, pero necesariamente conducen al mismo fin: a considerar que la vida del que está en gestación merece inferior protección que otros derechos en juego ${ }^{44}$.

La problemática del asunto, de este modo, no sólo radica en la pormenorizada elección de las causales de aborto, respecto de lo cual se suele aseverar que se trata de situaciones límite y 
graves, sino en que, cual sea la que se ocupe, denota la transformación de la vida humana gestacional en un bien depreciado, ya sea por negar la existencia de derechos a su respecto o por considerar que en esa determinada situación la vida vale menos que la integridad, la autonomía o incluso la vida predicable del sujeto ya nacido.

El argumento del estado de necesidad en referencia al aborto terapéutico no evita en lo absoluto tener que asumir la realidad antes mencionada, ya que ni siquierael estado de necesidad asociado con complicaciones en la salud de la madre justificala privación de la vida del hijo, salvo que de ello derive la reflexión acerca de que tal vida no ha de ser defendida del mismo modo y con la misma intensidad que el otro derecho en juego, lo cual, más que hacer referencia al estado de necesidad, hacereferencia al arbitrio con el cual el legislador ha decidido qué bienes y hasta dónde los protege, a expensas incluso del marco constitucional armonioso de los derechosfundamentales: "No existe estado de necesidad alguno que pueda justificar privar a otro de su vida, a la que tiene derecho. De allí que la admisión del aborto como un acto lícito ha de partir de la negación del derecho a la vida del concebido, por mucho que esta vida, como en su día señalara el Tribunal Constitucional español, se califique como un "bien" (no se sabe de quién)" 45 .

Muy distinto es el caso en el cual, corriendo peligro tanto la vida de la madre como la del hijo, se busque salvar a aquel que sea posible, aunque sea la madre la que en situaciones extremas tenga mejores posibilidades, pues tal acción no sólo está amparada por el Derecho sin necesidad de efectuar despenalización alguna, sino que además resulta parte de las múltiples decisiones que se pueden tomar en protección de las personas y que pueden tener aparejados resultados no queridos dadala limitación del obrar humano: "Las acciones médicas tienen todas como intención próxima o remota salvar la vida de una persona, y todas, al menos potencialmente, tienen efectos colaterales indeseados que deben ser previstos y sopesados. Cuando no se trata de pacientes embarazadas, lo que está en juego es la misma vida del paciente que se intenta salvar con la acción médica, la que se puede malograr por los efectos colaterales. En el caso de una paciente embarazada, una acción médica que intente salvar la vida de la madre puede poner en riesgo la vida del hijo. En estos casos, y siempre que concurran todas las circunstancias mencionadas y que los padres estén de acuerdo en asumir el riesgo, podría ser legítimo y hasta obligatorio realizar una acción médica que conduzca a la muerte del hijo, aun cuando ésta fuese prevista como segura. Esta manera de entender la situación en la prácticamédica tradicional es la que legitima la intervención médica en casos como embarazo ectópico complicado con huevo vivo, infección ovular grave e hipertensión maligna con riesgo inminente de encefalopatía hipertensiva (Besio, 1992; 1993; 1998; Gormaz et al., 1993; Gormaz et al., 1995, Oyarzún et al., $1992)^{46}$.

Sin embargo, aún cabe hacernos la pregunta sobre si, de modo real o aparente,puede considerarse que la situación de embarazo de alto riesgo importa un conflictoentre la vida del nasciturus y la vida de la madre, puesto que ello podría llevar a la siguiente reflexión: El sistema que impide la realización de un aborto ha optado a priori por la vida del hijo y aquel que admite el aborto ha optado a priori por la vida de la madre ${ }^{47}$, opciones diversas pero igualmente vulneratorias del derecho que ha sido tratado como "cenicienta". 


\section{c.2. ¿Es el embarazo de alto riesgo una situación de real o aparente conflicto entre la vida del nasciturus y la de su madre?}

Para responder esta pregunta es necesario considerar al nasciturus como un titular de derechos fundamentales. De lo contrario, si se le considera simplemente un miembro de la especie humana, el cual, en razón de su desarrollo o dependenciaimplantacional, no ha alcanzado tal titularidad, no es capaz de generar respecto de su vida conflicto alguno de derechos, pues su situación se encontrará jurídicamenteprotegida pero necesariamente supeditada a que tal protección no afecte los derechosmaterialmente garantizados ${ }^{48}$.

En consecuencia con lo anterior, el aparente o real conflicto de derechossólo puede predicarse allí donde tanto el nasciturus como su madre comparten la calidad de titulares de derechos, ya sea del derecho a la vida o de la integridad física o psíquica, puesto que la autonomía no puede ser ejercida de modo alguno por el primero.

Reconocido lo anterior, a nuestro juicio el embarazo de alto riesgo constituye una situación que se ha traducido en un conflicto artificial al que comúnmente se ha recurrido para buscar una solución a un conflicto distinto, que se plantea entre la vida del nasciturus y la autonomía de la madre y que sí representa severas dificultades en el orden tanto local como comparado:

i. Desde la perspectiva médica las situaciones de alto riesgo para la vida de la madre durante el embrazo implican tan alto o mayor riesgo para la vida del hijo en gestación, por lo cual la situación de bienestar/malestar a la que teóricamente se alude no constituye una realidad científica ni la situación ha de definirse por decidir sobre la muerte de uno de ellos sino, por el contrario, por la pronta acción salvadora a favor de ambos o la utilización de otras terapias no destructivas ${ }^{49}$, lo que no impide que las limitaciones de la ciencia médica puedan impedir que tal medida sea exitosa respecto de la madre y del hijo.

ii. La situación de embarazo contempla a dos pacientes, de tal modo conectados, que el compromiso del organismo de la gestante inevitablemente afecta al del gestado: “...Infección ovular, espontánea o provocada: la embarazada acude a urgencia obstétrica con fiebrealta, a veces en shock séptico y con el útero grávido con feto vivo o ya muerto; Embarazo ectópico. Los embarazos tubarios, o viscerales(riñones, páncreas u otros accesibles por el peritoneo) no pueden llegara término sin producir daño severo a la madre. El tubario es inviable a término y la rotura tubaria puede matar a la madre por hemorragia. Los peritoneales pueden llegar a término o a una edad gestacional compatible con la vida ex peritoneum; la patología del embarazo mismo: lapre-eclampsia y eclampsia que, cuando se presentan en forma severadesde muy temprano (complicada o producida por patología fetal); la mola hidatidiforme que se presenta clínicamente como mola completa.Corresponde en casi todos los casos a una concepción donde el núcleodel ovocito ha sido expulsado y el espermático se ha duplicado, por loque el cigoto tiene sólo información paterna. Cromosómicamente son46 XX (las YY son inviables). La mola no tiene forma de embrión nifeto (racimos vesiculosos) y frecuentemente deviene en tejido invasivo ose canceriza, aunque puede tener tejido identificable como embrionario en su origen ${ }^{50}$.

iii. Estas situaciones, como se ha dicho, son tan graves que ponen en riesgo vital a la madre y al hijo, ello en el caso que este último no esté ya muertopor paralización de su crecimiento u otras anomalías, por lo cual ni el médico tratante ni la madre ni su familia se encuentran en realidad ante la opción de 
determinar qué vida se ha de considerar más protegida: el responsable ejercicio de la Medicina indica salvar la vida o las vidas que sea posible dado el avance de la ciencia, el estado de los pacientes particularmente el desarrollo y peso del nasciturus-y los recursos de que se disponga. Por ello, considerar que la cura de estas patologías es la muerte del hijo previa jerarquización favorable al derecho a la vida de la madre no es otra cosa que hacer una definición jurídica abstracta sobre antecedentes que no gozan de materialidad en la práctica y que no se subsumen en principios o garantías constitucionales que justifiquen la elección.

Como se ha dicho, más bien la intención real de quienes propugnan este modelobusca despenalizar una conducta cuyo fundamento, mucho más allá del conflicto vida/vida, alude al conflicto vida/autonomía o vida/salud psicológica, lo cual sitúa al aborto terapéutico en la verdadera controversia sobre el aborto propiamente tal y no en una situación apartada y excepcional $^{51}$.

\section{c.3. Una forma de abordar el eventual o real conflicto vida/autonomía}

Este último presunto o real conflicto de derechos, a nuestro juicio, no puede resolverse por la vía de la jerarquización ni tampoco por la modalidad de ponderación de intereses o balancing test, pues necesariamente ello conduce a estimar que en ciertas y determinadas circunstancias los derechos son sacrificables o se sitúan en una posición de desmedro respecto de otros. En efecto: "Los métodos que criticamos -especialmente el balancing- llevan implícito un lógico corolario -aunque esto no se diga o quien los utiliza no repare en ello-: que los dos derechos alegados existen en el caso concreto, pero uno de ellos, del cual una de las partes es titular y lo ejerce, lo ha ejercido o lo ejercerá legítimamente, debe sacrificarse en aras de un contrincante superior en abstracto y a priori - tal es el caso de la categorización o jerarquización- o superior en concreto como ocurre en el método del balance- que será, pues, el derecho realmente eficaz"52.

De este modo, pretender solucionar los problemas que genera la toma dedecisiones en torno a un embarazo no deseado, "problemático" o que implique afectación de cualquier tipo para la madre estableciendo el rango que habrá de tenerla vida del hijo en este caso, implica evitar correr el riesgo de hacerse cargo de la esencia de los derechos y examinar si el contenido de los derechos de autonomía, de integridad física o psíquica puede implicar la disposición de otra vida humana, lo cual difiere sustancialmente de los efectos no queridos que sobre esa vida pueda tener la aplicación de una terapia o de un tratamiento médico.

Así, el legislador al hacer la estimación acerca de la equidad que importa la resolución del caso estableciendo una norma general, o el juez, cuando ha de hacersecargo de la situación particular conflictuada, no podrán directamente disponer de unarespuesta pretasada o de salir de la encrucijada "declarando" un derecho prevalenteal otro: en un escenario de derechos fundamentales, la determinación de contenido de los derechos respecto de su titular es lo que resulta determinante y a menudo se vislumbra que aquello que, de una parte, aparece como derecho, es más bien un interés o una expectativa que no corresponde necesariamente a una prerrogativa constitucionalmente garantizada, pues ésta tiene límites emanados -a diferencia delos criterios de la prevalencia- de su propia naturaleza: "Delimitar un derecho es establecer su contenido (haz de facultades, garantías y posibilidades de actuación) y sus fronteras o límites. En otras palabras, delimitar es determinar el ámbito de realidad protegido por el derecho lo que 
determina sus contornos/ Todo derecho en este sentido es limitado ya que ampara sólo el contenido del derecho garantizado constitucionalmente, el cual tiene presente el contenido de los demás derechos y bienes constitucionalmente garantizados/ El límite de un derecho es la frontera entre lo que algo es y lo que no es. El límite es parte de la estructura del derecho y considera todos los demás derechos y bienes constitucionalmente protegidos. El límite de un derecho presupone la existencia de un contenido constitucionalmente protegido prefijado dentro del cual conlleva un límite como contorno o frontera/ Los límites o fronteras de los derechos consideran los demás bienes y derechos constitucionalmente protegidos por el ordenamiento jurídico, constituyendo unsistema integrado y armónico" $" 53$.

Esta solución no implica desconocer las valoraciones culturales sobre los derechosque todo sistema es susceptible de hacer, que resultan el fundamento y trasfondo de latextualidad de los derechos garantizados constitucionalmente, pero tal existencia de valores o de decisiones sociales contingentes no puede afectar la cabida del derecho ni transformarlo en una cosa distinta a la que es, como por ejemplo un derecho que,sin mediar un disvalor alguno previsto en la Constitución, disminuye ostensiblementesu rango de protección al invocarse otro derecho por un tercero.

En esa perspectiva, no cabe duda que cualquier tipo de aborto, sin importar susmotivaciones, representa una decisión tomada frente a una realidad que agobia y afecta psicológicamente a la madre, ya sea por la imposibilidad de hacerse cargo deese hijo, porque ser madre en ese momento o en esas circunstancias no está previsto,porque las condiciones del hijo mismo no son satisfactorias, etc. La malla de las aflicciones asociadas con el aborto es interminable, por lo cual remitir la situación a la presencia de tal afectación para considerar que ello autoriza a la disposición de la vida ya no sólo importa privilegiar el estado psicológico de una persona sobre la vida de otra sin buscar mejores soluciones sino que, lo que es mucho más grave, considerar en realidad que todo aborto está justificado en la medida que el embarazorepresente un perjuicio, malestar o sufrimiento para la madre: "He de recordar que la Organización Mundial de la Salud (OMS) entiende por salud el estado de perfectobienestar físico, psíquico y social y no sólo la ausencia de lesión o enfermedad. ¿Cuándo se logra ese estado de perfecto bienestar? ¿Qué puede ocasionar en una mujer, esté o no embarazada, una afección a ese bienestar físico, mental o social? Podría decirse que todo o nada. La salud va más allá del estado de bienestar físico. Si con el término "salud" la OMS y los organismos internacionales de derechos humanos abarcan las condiciones psíquicas y sociales de la mujer embarazada, ¿puede excluirse algo para justificar la acción abortiva? Simplemente no, porque se ha incluido todo. Sí, todo"54.

Ello, sin duda, genera dicotomías profundas: nos repugnaría pensar que una mujer esté liberada de cuidar a un hijo gravemente enfermo porque la enfermedad podría serle contagiada o que la única pena posible para un violador fuera la de muerte, por reprochable y atroz que sea su delito. Tampoco nos parecería tolerable que los progenitores decidieran aplicar el infanticidio a niños con discapacidades severas o que se negaran a brindar alimentos a menores con escasas posibilidades de sobrevida. Sin embargo, la afectación psicológica que tales hechos generan en un individuo, justificadamente por lo demás, pueden parecer sencillamente como validaciones jurídicas para disponer de la vida de esos seres humanos en esascircunstancias o del producto de la concepción sucedida en medio de un acto de indigno forzamiento y todo ello, según la laxitud 
legal o interpretativa, puede ser "aborto terapéutico", muerte que pone alivio al padecimiento de otro.

Es evidente que una de las más pueriles pero efectivas razones por las cualesel aborto, en los mismos casos en que nos parecía un crimen deleznable si se tratara de seres ya nacidos, puede configurarse como una solución neutra es,por una parte, la invisibilidad del nasciturus -por más que la difusión científicanos impida hoy declararnos ignorantes de su desarrollo semana a semana, mes a mes-, y por la otra, la natural simpatía que merece el dolor o el padecimiento del cooptado social, de aquel que forma ya parte del grupo, que vive entre nosotros e interactúa en la sociedad civil. Sin embargo, ¿esa simpatía o solidaridad es el fundamento de la diferenciación entre derechos? ¿El sufrimiento de un serhumano constituye, en el ámbito de los derechos fundamentales, la legitimación de la muerte de otro, asumida además como una decisión vinculante y general del Estado?

A fin de evitar tener que hacerse cargo de estas preguntas, que están másbien dirigidas al colectivo que a la mujer que decide practicarse un aborto, algunos autores estiman que la sociedad no está llamada a tomar la decisión sino tan sólo a restarse de actuar prohibitiva o punitivamente, habida consideración que, si bien los derechos surgen desde el inicio de la vida humana en relación con la madre del nasciturus, las obligaciones correlativas se adquieren por un acto de voluntad y aceptación ${ }^{55} \mathrm{y}$, en tal evento, las justificaciones para la decisión estánobviamente marcadas de subjetividad y, como tales, no representan un criteriodeterminante.

\section{c.4. Constitución chilena de 1980 y conflicto de derechos}

\section{i. la Carta de 1980 no distingue rangos entre los derechos fundamentales}

La Carta de 1980 no ha previsto la jerarquización de los derechos contenidos en ella o la subestimación de estos derechos según los ejerzan ciertos titulares por el contrario, demanda la adecuada ponderación y armonización del orden constitucional: "El principio de unidad de la Constitución exige que el legislador realice elmáximo esfuerzo para configurar y regular los derechos en un sistema donde cada uno de ellos colisione lo menos posible con otros, donde los derechos constituyan círculos tangentes y no círculos secantes que se invadan unos a otros, lo que exige la adecuada ponderación y un eventual sacrificio mínimo de cada derecho que exige el principio de proporcionalidad que debe emplear necesariamente el legislador en la regulación de los derechos" ${ }^{\prime 5}$.

\section{ii. La remisión a la ley del artículo $19 \mathrm{~N}^{\circ} 1$ ha hecho considerar, sinembargo, que la protección de la vida del que está por nacer es un tema estrictamente legal}

La redacción que el Constituyente hizo en el artículo $19 \mathrm{~N}^{\circ} 1$ en el sentido que la ley protege la vida del que está por nacer ha servido para que parte de la doctrina nacional sostenga que ello implicaría un tácito beneplácito para que precisamente el legislador determinara los límites y la forma de proteger ese derecho, loque ocurriría idénticamente a propósito de una similar redacción del Pacto de San José de Costa Rica ${ }^{57}$. La revisión de las actas de la Comisión de Estudios, citadas muchas veces por quienes no las consideran sin embargo hábiles para interpretar la Constitución, dan cuenta de la divergencia en la protección de la vida del que está 
por nacer por parte de los comisionados y de su consideración que la penalización del aborto es tema legal, pero mal puede traducirse de ellas la idea que tales comisionados consideraran que el derecho a la vida del nasciturus descansará sólo en las manos de la ley.

Si bien numerosas materias contenidas en la Constitución importan remisionesa la ley, sea para penalizar conductas, establecer tipos penales, procedimientos, etc., ello no disminuye en lo absoluto el imperio del ya citado artículo $19 \mathrm{~N}^{\circ} 26$, que constituye decididamente el modo en el cual la Carta Fundamental ofrece un criterio poderoso al legislador para dirimir reales o aparentes conflictos dederechos: hay que acudir a la esencia de éstos, pues ella no puede ser afectadani aun por quien dicta normas legales por mandato de la Constitución; luego, menos podrá ocurrir ante situaciones puntuales de encuentro controversial entrebinomios de derechos.

\section{iii. El propio artículo $19 \mathrm{~N}^{\circ} 26$ autoriza al legislador para regular lasgarantías que la Constitución establece o para limitarlas preservando el contenido esencial de los derechos}

La regulación de un derecho por el legislador podría consistir en la concretización legislativa del derecho como en el establecimiento de restricciones en algunos elementos que no forman parte del contenido esencial del mismo, las que deben justificarse de acuerdo al principio de proporcionalidad que se encontraría implícito en el texto constitucional en cuanto Estado de Derecho.

En esa perspectiva, el Tribunal Constitucional ha manifestado que "Un derechoes afectado en su 'esencia' cuando se le priva de aquello que es consustancial, de manera tal que deja de ser reconocible. Se impide su 'libre ejercicio' en aquellos casos en que el legislador lo somete a exigencias que lo hacen irrealizable, lo entraban más allá de lo razonable o lo privan de tutela jurídica" $" 58$.

\section{iv. ¿De qué modo podría vulnerarse el artículo 19 № 26 en la resolución de un eventual conflicto de derechos?}

Hay restricciones que forman parte de la esencia de un derecho por ser inmanentes a él y establecerlas no representa un menoscabo a dicho derecho, sino parte de los límites naturales del mismo; así, forma parte de la esencia del derechode propiedad la limitación que éste sufre derivada de su función social" ${ }^{\prime 5}$. En tal sentido, el contenido de los derechos no es inabarcable ni deviene en un mar sin límites, de lo cual no es excepción el derecho a la vida, razón por la cual se admite la vulneración de la vida en un acto de legítima defensa, el cual, en todocaso, no tiene por objeto matar sino defender la propia vida y la integridad anteun agresor ilegítimo.

¿Ha de entenderse al nasciturus como agresor cuando el embarazo genera afectación de la madre? Debemos descartar tal hipótesis no sólo por la total imposibilidad de actuar como agresor del que está por nacer, tanto por su ausencia de voluntad como por su incapacidad para actuar, sino además porque el Derecho Penal es suficientemente explícito en orden a que, aun en caso de agresión, ésta debe ser ilegítima y, por ello, reprochable ${ }^{60}$. La situación de padecimiento, enfermedad o aun compromiso vital de la madre tiene por referente su embarazo y a veces 
patologías o condiciones previas, pero jamás se relaciona con la existencia misma de otro ser humano como tal.

Por esta causa, no puede entenderse que tales desgraciadas afectaciones de la madre constituyan un límite natural o jurídicamente admisible del derecho a la vidadel hijo, tanto en razón de la total desvinculación de su derecho con la situación que afecta al titular del otro, como porque mal podría entenderse como limitación natural de un derecho la tendencia a su propia desaparición, pues no se propone verla especie descender en el nivel de cuidado sino directamente considerar admisibleuna acción matadora, lo que directamente vulnera los números $1^{\circ}$ y 26 del Artículo 19 de la Carta Fundamental.

\section{Iv. A modo de conclusión: Despenalizar el "aborto terapéutico en Chile", inutilidad e inconstitucionalidad de una propuesta legislativa}

\section{Despenalización inútil: el grave riesgo durante el embarazo se puede tratar por el médico sin necesidad de despenalización alguna}

Las situaciones de grave riesgo en el embarazo son siempre conmovedoras, no sólo por el sufrimiento y temor que representan para la mujer y la familia sino porque no están motivadas normalmente por descuidos o negligencias, y tampoco por patologías de base o complicaciones asociadas con el proceso del embarazo mismo. Por lo injustas que nos parecen, a menudo son presentadas como parte de la casuística que justificaría despenalizar el aborto, brindando así una solución a la mujer y a los suyos, evitándole morir o arriesgar que ello ocurra.

La verdad es que asumir médica y terapéuticamente el embarazo de riesgo se encuentra dentro de las facultades y de los deberes del médico que los exige el Derecho de ordinario: no hacerlo podría constituirse en una acción que alcanzaría hasta responsabilidades penales de su parte por una negligencia inexcusable oincluso por dolo manifiesto.

Ante tales circunstancias el médico aplica las medidas que la lex artis indica,entre las que se puede considerar la interrupción del embrazo como última ratio $^{61}$, pero, como es obvio, no con el propósito de privilegiar a uno de los pacientes en desmedro del otro sino procurando realizar una acción salvadora de ambos. Tal posibilidad es plenamente ajustada al Derecho vigente y no se traduce en decisiones de conflictuación de derechos sino en la prestación médica debida a los dos pacientes que penden del embarazo en esta situación: la madre y su hijo.

Tal posibilidad se considera incluso admisible por el Magisterio de la Iglesia Católica: "Es posible que en la práctica de la medicina el médico, con el fin de salvara sus dos pacientes, pudiera estimar que la conducta a seguir sea la de adelantar el parto, aunque ello implique riesgos para la vida del recién nacido por inmadurez. Esta acción la realiza con el convencimiento de que sacarlo del útero representa la única posibilidad de sobrevida para el concebido y para la madre. Para un médico bien intencionado que ha puesto lo mejor de sí por mantener el embarazo, puede llegar un momento en que razonablemente juzgue que la única posibilidad desalvar a ambos es adelantando el parto. El médico que tiene la intención de salvar a ambos no interrumpe el proceso de gravidez para salvar al menos la vida de la madre, sino que su intención es siempre salvar la vida de los dos. Su acción es una terapia lícita, y no puede ser 
considerado un aborto procurado. En esta línea va el magisterio de la Iglesia, a la luz de lo dicho por Pío XII en el año 1951, en un discurso dirigido a los participantes del Congreso de la Unión Católica Italiana de Obstetras, cuando postuló que ...es erróneo poner el asunto en términos de la vida del niño o de la madre. No, ni la vida de la madre ni la del niño pueden ser objeto de un acto de directa supresión. Solamente puede existir una exigencia. Hacer todoesfuerzo por salvar ambas vidas. Él ha excluido claramente todo aborto directo, es decir, aquel que se realiza como fin o como medio, pero no ha excluido acciones en sí mismas legítimas que lleven grabadas un riesgo, incluso vital" 62 .

La aplicación de la doctrina del doble efecto o voluntario indirecto al caso esplenamente compatible con la ausencia de intención matadora de la conducta, lacual es propia del dolo del delito de aborto: "Se denomina principio, doctrina, regla o razonamiento del doble efecto al principio de razonamiento práctico que sirve para determinar la licitud o ilicitud de una acción que produce o puede producir dos efectos, de los cuales uno es bueno y el otro es malo. El principio recoge algunos de loselementos centrales de la doctrina tomista sobre el acto humano y la responsabilidad moral. En particular, se basa en la relevancia de la distinción entre voluntariedaddirecta y voluntariedad indirecta. Los seguidores de Tomás de Aquino llamarondirectamente voluntario a aquello que forma parte del plan de acción del agente, esto es, a lo que él se propone alcanzar como fin de la acción y a lo que busca comomedio para conseguir ese fin. Por el contrario, llamaron indirectamente voluntarioa aquellos efectos de la acción voluntaria, que el agente prevé o debe prever, peroque no busca ni como fin ni como medio, sino que sólo acepta, permite o tolera en lamedida en que se encuentran ligados a lo que directamente quiere" 63 .

1.

Si aplicamos este principio a la acción del médico en un caso de embarazo congrave riesgo, su acción se dirige y tiene una intención salvadora; sin embargo está en conocimiento que de ello podría derivarse un mal no querido, esto es, la muerte de uno de sus pacientes: "También se ha argumentado a favor de la relevancia de la distinción directo/indirecto apelando a algunas diferencias usualmente aceptadasen prácticas como el arte médico o la guerra. El reconocimiento común de estas diferencias es una señal de que detrás de ellas existe una verdadera significación moral. Este argumento se suele exponer mostrando el contraste que existe entre casos donde el efecto malo es querido como medio y casos donde el efecto malo es meramente previsto/ La distinción entre voluntariedad directa y voluntariedad indirecta funda también la que a su vez existe entre aborto directo y aborto indirecto.En el primero la muerte del feto entra en el ámbito de la intención, ya sea como fin o como medio. En el segundo la occisión es sólo indirecta, esto es, la muerte no se intenta ni como fin ni como medio, sino que sólo se acepta como efecto colateral. Esta distinción cobra especial relevancia en todas aquellas situaciones en las que la vida de la madre sólo puede salvarse con una acción que involucra la muerte del feto. En esta hipótesis, si la occisión es sólo indirecta, la acción se justifica conforme a la regla del doble efecto, pues la salvación de la vida de la madre siempre puede considerarse una razón proporcionalmente importante. Un ejemplo común, ya mencionado, es el de la mujer embarazada que padece cáncer cervical y solo puede librarse de la enfermedad sometiéndose a una histerectomía. Por consiguiente,una norma que prohíba el aborto de modo absoluto -como también una que de esa manera prohíba el 
homicidio en general- sólo puede referirse a aquel que es causado intencionalmente, es decir, al aborto directo" ${ }^{\prime 64}$.

Del mismo modo anterior, si ha de aplicarse a la mujer, para evitar que muera,una terapia que puede ser incompatible con el embarazo, se suministrará ésta comoultima ratio, particularmente si aún el feto no es viable, pero no estará impedido de hacerse pues el derecho a la vida tanto de la madre como del hijo importan una relación con la protección de la salud que es debida a ambos y no sólo al hijo.

Ello no representa un modo de abordar un conflicto de derechos sino estimar válidas las prestaciones y acciones de salud y de resguardo de la vida que se consideran parte del contenido esencial del derecho, tanto de la madre como del hijo, y, por tal causa, no importan un aborto provocado ni representan modificación algunaal estatuto penal chileno de la prohibición de aborto en todas sus formas.

\section{Despenalización inconstitucional: atentado a la esencia del derecho a la vida del nasciturus}

Como ya se ha dicho, la referencia a la salud de la madre en los términos amplios que puede significar, como a la viabilidad fetal ${ }^{65}$, para justificar un aborto, constituye una jerarquización desfavorable del derecho a la vida del nasciturus yuna vulneración a la esencia del derecho fundamental a la vida que le está expresamente cautelado por la Constitución.

Tales situaciones, y así lo ha demostrado la experiencia comparada ${ }^{66}$, no son más que puertas de entrada hacia una creciente despenalización del aborto, continuando con causales eugenésicas, violación, incesto, hasta llegar, como es lógico en esta sucesión, al aborto libre.

La asistencia médica y psicológica a la madre es plenamente válida, como asimismo el desarrollo de todas las políticas sociales dirigidas a la protección materno-infantil durante el embarazo, parto y posterior a él, incluida la asistencia antela muerte próxima del nacido. Sin embargo, no le es dado al legislador ni al juez dirimir un eventual conflicto de derechos considerando que la Constitución ha de retirar su protección cuando un sujeto esté próximo a morir o cuando situaciones diversas afecten a su madre y le produzcan un padecimiento para el cual probadamente la solución y el consuelo no es la muerte procurada de su hijo.

\section{Citas}

${ }^{1}$ Abogada UC, Candidata a Doctora en Derecho por la Universidad de La Coruña, España.Profesora de Derecho Constitucional y de Bioética y Persona en la Pontificia Universidad Católicade Chile, miembro del Centro de Estudios para el Derecho y la Ética Aplicada-CEDAP UC. 
${ }^{2}$ Seguían el modelo ya propuesto por otra iniciativa legislativa contenida en mociónparlamentaria de 23 de enero de 2003, Boletín $N^{\circ} 3197-11 .{ }^{3}$ Las cursivas son nuestras.

${ }^{4}$ Sucedida en virtud de la Ley 18.826 de 15 de septiembre de 1989, disponiéndose en su lugar en el artículo 119 que "No podrá ejecutarse ninguna acción cuyo fin sea provocar un aborto". 5 Las cursivas son nuestras. ${ }^{6}$ Cuyo sentido primordial es impedir que el Estado mate seres humanos, legalice la muerte de éstos o de algún modo la permita: Vid. Enrique Peñaranda Ramos, "Homicidio" en Miguel Bajo Fernández, Compendio de derecho penal (Madrid, Centro de Estudios RamónAreces, 2003, pág. 26.

${ }^{7}$ CS 1955, RDJ LII, 4-74.

${ }^{8}$ Etcheberry, A. El Derecho Penal en la jurisprudencia, Tomo II ( ${ }^{\text {a }}$ Edición, Santiago, Editorial Jurídica, 1987) pág. 346.

${ }^{9}$ Ibíd.

${ }^{10}$ De hecho, los ordenamientos jurídicos se resisten a castigar el aborto producido por la omisión de cuidado de la propia madre.

${ }^{11}$ Zapata P. Persona y embrión humano: Nuevos problemas legales y su solución en el derecho chileno. Revista Chilena de Derecho, Volumen 15 (Santiago, Pontificia Universidad Católica de Chile, 1998) pág. 382.

${ }^{12}$ Garrido M. Derecho Penal Especial, Tomo III (Reimpresión de la $1{ }^{\text {a }}$ Edición, Santiago,Editorial Jurídica, 2001) pág. 97.

${ }^{13}$ De hecho, el Anteproyecto de nuevo Código Penal elaborado por el Foro Penal ubica al aborto en el Título II del Libro II del Código, inmediatamente a continuación del Título I sobre Homicidio y Lesiones: Anteproyecto de Código Penal Chileno de 2005, elaborado por la Comisión Foro Penal, Polít. crim. n. ${ }^{\circ}$ 1, D1, pág. 22.

${ }^{14}$ Este inciso fue modificado en virtud de la reforma constitucional contenida en la Ley $\mathrm{n} .{ }^{\circ}$ 19.611, que reemplazó la palabra "hombres" por "personas" en él, lo que sin embargomantiene indemne la interpretación proporcionada.

${ }^{15}$ El texto del artículo $1^{\circ}$ de la Ley $\mathrm{N}^{\mathrm{o}} 20.120$ que regula la investigación científica en el ser humano, su genoma y prohíbe la clonación humana, establece lo siguiente: "Esta ley tiene por finalidad proteger la vida de los seres humanos, desde el momento de la concepción, su integridad física y psíquica, así como su diversidad e identidad genética, en relación con la investigación científica biomédica y sus aplicaciones clínicas”. El tenor de este artículo es una confirmación del modelo constitucional de protección de la vida del que está por nacer desde el momento de su concepción. ${ }^{16}$ Se cita el fallo del Tribunal Constitucional chileno sobre la llamada píldora del día después, de fecha 18 de abril de 2008. 
${ }^{17}$ Comisionado Alejandro Silva Bascuñán, Actas Oficiales de la Comisión de Estudios de la Nueva Constitución, sesión № 84, pág. 16.

${ }^{18}$ Actas Oficiales de la Comisión Constituyente $\mathrm{N}^{\circ} 88$ de 19/11/1974. Vid. tambiénN ${ }^{\circ} 84$ de 4/11/1974 p. 13, n. ${ }^{\circ} 89$ de 21/11/1974 pág. 9 , n. ${ }^{\circ} 87$ pág. 11-23, n. ${ }^{\circ}$ N 90 25/11/1974 pág. 15-20 y n. ${ }^{\circ} 94$ de 12/12/1974 pág. 9; Informe preparado por la Mesa sobre las ideas precisasde anteproyecto de una Nueva Constitución Política de Estado, Párrafo 50 inciso $6^{\circ}$ y n. ${ }^{\circ} 407$ de 9/08/1978 pág. 3339-3340.

${ }^{19}$ Vid. estudio detallado de esta materia en Ángela Vivanco Martínez, Curso de Derecho Constitucional, Tomo II, Aspectos dogmáticos de la Carta Fundamental de 1980 (Santiago,Ediciones Universidad Católica, 2004) pág. 245-272.

${ }^{17}$ Comisionado Alejandro Silva Bascuñán, Actas Oficiales de la Comisión de Estudios de la Nueva Constitución, sesión № 84, pág. 16.

${ }^{18}$ Actas Oficiales de la Comisión Constituyente $\mathrm{N}^{\circ} 88$ de 19/11/1974. Vid. tambiénN ${ }^{\circ} 84$ de 4/11/1974 p. 13, n. ${ }^{\circ} 89$ de 21/11/1974 pág. 9 , n. ${ }^{\circ} 87$ pág. $11-23$, n. ${ }^{\circ} \mathrm{N} 90$ 25/11/1974 pág. 15-20 y n. ${ }^{\circ} 94$ de 12/12/1974 pág. 9; Informe preparado por la Mesa sobre las ideas precisasde anteproyecto de una Nueva Constitución Política de Estado, Párrafo 50 inciso $6^{\circ}$ y n. ${ }^{\circ} 407$ de 9/08/1978 pág. 3339-3340.

${ }^{19}$ Vid. estudio detallado de esta materia en Ángela Vivanco Martínez, Curso de Derecho Constitucional, Tomo II, Aspectos dogmáticos de la Carta Fundamental de 1980 (Santiago,Ediciones Universidad Católica, 2004) pág. 245-272.

${ }^{20}$ Dides C. Aportes al debate sobre el aborto en Chile: Derechos, Género y Bioética, ActaBioethica 2006; 12(2):219-22.

${ }^{21}$ No obstante, de las normas constitucionales e internacionales no se deduce un mandatode despenalización del aborto ni una prohibición a los legisladores nacionales para adoptarnormas penales en este ámbito. De tal forma que el Congreso dispone de un amplio margen de configuración de la política pública en relación con el aborto. Sin embargo, dicho margen no es ilimitado. Aun en el campo penal de dicha política, el legislador ha de respetar dos tipos de límites constitucionales, como lo ha resaltado esta Corte. En efecto, al legislador penal, en primer lugar, le está prohibido invadir de manera desproporcionada derechos constitucionales y, en segundo lugar, le está ordenado no desproteger bienes constitucionales, sin que ellosignifique desconocer el principio de que al derecho penal, por su carácter restrictivo de las libertades, se ha de acudir como última ratio: Sentencia Corte Constitucional de ColombiaC-355/06 de 10 de mayo de 2006 (texto completo en http://200.4.48.33/mujeres/menu_superior/Doc_basicos/5_biblioteca_virtual/6_derechos_sexuale s_rep/10.pdf, sitio consultado en julio de2009), que despenaliza algunas figuras de aborto en Colombia, pero sin embargo reitera que las prohibiciones que se mantienen no importan 
infracción de los tratados internacionales aplicables.Luego nos referiremos a la parte sustantiva de este fallo.

${ }^{22}$ Sullivan, D. WHRnet, Enero 2004, en http://www.awid.org/esl/Temas-y-Analisis/Library/ElProtocolo-Facultativo-de-la-CEDAW-y-su-aplicabilidad-en-el-terreno, sitio consultado en julio de 2009.

${ }^{23}$ Barrantes M. de la C., Mercado E. El aborto terapéutico en Nicaragua: el diálogo comoparte de la solución al conflicto, Acta Bioethica. 2008; 14(1):106-110. ${ }^{24}$ Hermosilla J. P. Contrapunto: el aborto terapéutico. Revista Chilena de Derecho, vol. 36 n. ${ }^{\circ}$ 1, pág. 205-208 [2009].

${ }^{25}$ Van Weezel A. Contrapunto: el aborto terapéutico (citado).

${ }^{26}$ Besio M. Consideraciones éticas sobre el aborto terapéutico en Boletín de la Escuela deMedicina, Vol. 27, n. ${ }^{\circ}$ 1, 1998, en

http://escuela.med.puc.cl/publ/Boletin/Etica/ConsideracionesEticas.html, sitio consultado en julio de 2009.

${ }^{27}$ Normas de Atención al Aborto. Dirección General de Atención Médica, Dir. Materno Infantil. Departamento de Atención Integral a la Mujer, Nicaragua, agosto 1989.

${ }^{28}$ Precht J. Consideraciones ético-jurídicas sobre el Aborto Terapéutico. Revista Chilena de Derecho, Vol. 19 n. ${ }^{\circ}$ 3, 1992, pág. 510.

${ }^{29}$ Valenzuela, C.Y. Ética científica del aborto terapéutico. Revista Médica de Chile v.131 n. 5 Santiago mayo 2003, pág. 562-568.

${ }^{30}$ Cotes M.I. Las despenalización del aborto en Colombia: Una solución innecesaria.

${ }^{31}$ Romeo C.M. I El Médico y el Derecho Penal. La actividad curativa (Barcelona, Bosch,1981), pág. 185.

${ }^{32}$ El estado de completo bienestar físico, mental y social y no solamente la ausencia de afecciones o enfermedades (OMS, 1948). La misma OMS admite la dualidad de posibilidades del aborto terapéutico, considerando la existencia de una clasificación que distingue entre la situación del embarazo pone en peligro la vida de la madre (aborto terapéutico por razones estrictas) o afecta a su salud física o psíquica (aborto terapéutico por razones amplias).

${ }^{33}$ Serani A. El estatuto antropológico y ético del embrión humano, Persona y Bioética, Universidad de La Sabana, Colombia, Vol 5, n. 13 (2001), en http://aquichan.unisabana.edu.co/index.php/personaybioetica/article/view/930/1782, sitio consultado en julio de 2009. Lascursivas son nuestras. Vid. también, de la autora, Aspectos jurídicos del llamado aborto terapéuticoen Chile, Ars Medica Vol. 4 n. ${ }^{\circ}$ 6- 2002, pág. 155-179.

${ }^{34}$ En la mayoría de los Estados miembros del Consejo de Europa la ley autoriza el abortopara salvar la vida de la madre. En la mayoría de los otros países de Europa el aborto se autoriza por 
distintas razones, en particular la conservación de la salud física y mental de la madre y también en las situaciones de violación o de incesto, en caso de malformaciones en el feto o paramotivos económicos y sociales y, en algunos países, por un sistema libre de plazos: Resolución 1607 (2008) de la Asamblea Parlamentaria del Consejo de Europa.

${ }^{35}$ Hooft P. F. Anencefalia: consideraciones bioéticas y jurídicas, Acta bioethica, v.6 n. ${ }^{\circ} 2$ Santiago dic. 2000.

${ }^{36}$ Peces-Barba G. Curso de derechos fundamentales. Teoría general, Madrid, UniversidadCarlosIII de Madrid y Boletín Oficial del Estado, 1999, pág. 594.

${ }^{37}$ Rodríguez R. Derecho Constitucional (México DF, UNAM, 1978) pág. 378.

${ }^{38}$ Castillo L.F. ¿Existen los llamados conflictos entre derechos fundamentales? Revista Mexicana de Derecho Constitucional n. ${ }^{\circ}$ 12, www.juridicas.unam.mx/publica/rev/cconst/cont/12/ard/ard4.htm - 104k, sitio consultado en junio de 2008.

${ }^{39}$ En la obra La interpretación constitucional de los derechos fundamentales. Una alternativaa los conflictos de derechos, de Pedro Serna y Fernando Toller, La Ley, Buenos Aires, 2000, considera que las tesis conflictivistas, como veremos, a la postre resultan en el sacrificio de uno de los derechos, lo que implica el desmedro y la pérdida de algunos derechos de su calidad de fundamentales, para convertirse unos en derechos príncipe y otros en derechos cenicienta, cuya medianoche es cruzarse con un derecho considerado más fuerte.

${ }^{40}$ Vid. Antonio Bascuñán Rodríguez. Límites a la prohibición y autorización legal del aborto consentido en el derecho Constitucional comparado. Revista de Derecho Público, 63 (2001), I, pág. 209 sig., esp. pág. 212-223.

${ }^{41}$ Silva J-M. Los indeseados como enemigos. La exclusión de seres humanos del Status Personae. Revista Electrónica de Ciencia Penal y Criminología, 2007, http://criminet.ugr.es/recpc/09/recpc09-01.pdf ISSN 1695-0194 [RECPC 09-01 (2007), 31 ene]

${ }^{42}$ Castillo L.F., óp. cit.

${ }^{43}$ Prieto L. Observaciones sobre las antinomias y el criterio de ponderación. Diritti\&questionipubbliche - $\mathrm{n} .2$ agosto 2002, pág. 99.

${ }^{44}$ Desde el punto de vista constitucional, el proyecto, al declarar no punible el aborto en determinados supuestos, viene a delimitar el ámbito de la protección penal del nasciturus, que queda excluido en tales casos en razón de la protección de derechos constitucionales de la mujery de las circunstancias concurrentes en determinadas situaciones. Por ello, una vez establecida la constitucionalidad de tales supuestos, es necesario examinar si la regulación contenida en el art. 417 bis del Código Penal, en la redacción dada por el Proyecto, garantiza suficientemente el resultado de la ponderación de los bienes y derechos en conflicto realizada por el legislador, de forma tal que la desprotección del nasciturus no se produzca fuera de las 
situaciones previstas nise desprotejan los derechos a la vida y a la integridad física de la mujer, evitando que el sacrificiodel nasciturus, en su caso, comporte innecesariamente el de otros derechos constitucionalmenteprotegidos. Y ello porque, como hemos puesto de manifiesto en los fundamentos jurídicos 4 y 7 de la presente Sentencia, el Estado tiene la obligación de garantizar la vida, incluida la del nasciturus (art. 15 de la Constitución), mediante un sistema legal que suponga una protección efectiva de la misma, lo que exige, en la medida de lo posible, que se establezcan las garantías necesarias para que la eficacia de dicho sistema no disminuya más allá de lo que exige la finalidaddel nuevo precepto. Sentencia del Tribunal Constitucional Español 53/1985 de 11 de abril, con ocasión del examen del texto definitivo del Proyecto de Ley Orgánica de reforma del Art. 417 bis del Código Penal.

${ }^{45}$ Silva J-M., óp. cit. Su referencia al Tribunal Constitucional español alude al fallo STC 53/ 1985, de 11 de abril, referido en la cita anterior.

${ }^{46}$ Serani A., óp. cit.

${ }^{47}$ Empero, si bien no resulta desproporcionada la protección del nasciturus mediante medidas de carácter penal y en consecuencia la sanción del aborto resulta ajustada a laConstitución Política, la penalización del aborto en todas las circunstancias implica la completa preeminencia de uno de los bienes jurídicos en juego, la vida del nasciturus, y el consiguiente sacrificio absoluto de todos los derechos fundamentales de la mujer embarazada, lo que sin duda resulta a todas luces inconstitucional/... Llevar el deber de protección estatal a la vida en gestación en estos casos excepcionales hasta el extremo de penalizar la interrupción del embarazo,significa darle una prelación absoluta a la vida en gestación sobre los derechos fundamentales comprometidos de la mujer embarazada, especialmente su posibilidad de decidir si continúa o no con un embarazo no consentido. Una intromisión estatal de tal magnitud en su libre desarrollode la personalidad y en su dignidad humana privaría totalmente de contenido estos derechos, y en esa medida resulta manifiestamente desproporcionada e irrazonable. La dignidad de la mujer excluye que pueda considerársele como mero receptáculo, y por tanto el consentimiento para asumir cualquier compromiso u obligación cobra especial relieve en este caso ante un hecho de tanta trascendencia como el de dar vida a un nuevo ser, vida que afectará profundamente a la de la mujer en todos los sentidos. Sentencia de la Corte Constitucional de Colombia 355/06 de 10 de mayo de 2006 citada.

${ }^{48}$ Así las cosas, el derecho solamente reconoce personalidad jurídica a aquel ser que ha nacido, y por tanto posee derechos ciertos. En otras palabras, mientras el ser no nazca lo que existen son intereses susceptibles de protegerse, o más exactamente prestaciones en favor de éste,sin que ello traiga consigo que se le esté reconociendo personalidad jurídica. Los seres humanoscon personalidad jurídica tienen la posibilidad de obligarse, y por ende pueden adquirir bienes y servicios, contratar, fungir en calidad de acreedores o deudores, tienen una serie de deberes con el Estado, como pagar impuestos o prestar el servicio militar. Situación jurídica no presente en aquellos intereses sin personalidad jurídica, que si bien pueden ser protegidos por el derecho no implica ello de suyo el reconocimiento de la personalidad jurídica.Por consiguiente, el nasciturus es ser protegido por el derecho pero claramente no tiene personalidad jurídica; y no la tiene por cuanto no puede adquirir bienes o servicios, contratar, pagar impuestos, etc. De aceptarse una tesis contraria, esto es, que el nasciturus tiene personalidad jurídica, sus derechos siempre 
prevalecerían sobre el de la madre: un ser que no expresó su voluntad para venir al mundo y que además está indefenso; enfrentado a quien la trajo al mundo sin su voluntad y con más poder que el feto, en caso de conflicto, deberían primar los derechos del más débil. Solución muy útil la brindada por el magistrado Jaime Araújo Rentería en su aclaración de voto a la Sentencia de la Corte Constitucional de Colombia 355/06 de 10 de mayo de 2006 citada, pues a fin de no protegerlo dada su debilidad e indefensión, resulta útil al ordenamiento no considerarlo titular de derechos.

${ }^{49}$ Hoy, dados los grandes avances en el manejo clínico de las enfermedades que pueden poner en grave riesgo la vida de la mujer gestante, ya ningún médico verdaderamente competenteestima que el aborto se presenta como el tratamiento de elección de ninguna enfermedad de la madre: el aborto no es solución superior a todas las demás alternativas de tratamiento. Por ello, el médico no está moralmente obligado ni a proponerlo ni a aplicarlo. Sin necesidad de invocar la objeción de conciencia, el médico, basado en el arte médico del momento, puede rechazar el aborto sobre bases estrictamente científicas. No es que se niegue, solamente por razones morales, a realizar el aborto, sino que ofrece alternativas de tratamiento que no sólo brindan una soluciónal problema médico de la gestante sino que, además, respetan la vida del no nacido: María de la Luz Casas. Derechos del médico: Aspectos éticos y jurídicos de la objeción de conciencia en Persona y Bioética, Universidad de La Sabana, Colombia, Vol 4 n. ${ }^{\circ}$ 9, 2000.

${ }^{50}$ Valenzuela, C.Y., óp. cit. Transcribimos sólo los casos más graves, ya que el autor da cuenta de varios otros que, con tratamiento adecuado, permiten llevar a término el embarazo con un pronóstico positivo.

${ }^{51}$ A saber: a) conflicto de derechos de distinto titular (el feto y la madre), en el evento queal no nato se le considere persona en el ámbito de la legislación interna, o b) como un problema de límites a los derechos reproductivos de la mujer, en el caso de que el feto sea considerado un objeto de protección por parte del Derecho doméstico. En una u otra vertiente, la jurisprudencia internacional ha entendido que están involucrados derechos de la mujer, que varían en función de los supuestos de hecho. Así, se ha determinado que, de manera general, concurre el derecho ala intimidad en lo relativo al control de la sexualidad; y, eventualmente, el derecho a la vida o a la salud de la madre en supuestos de aborto terapéutico, o, incluso, el derecho a no ser sometido a tortura, tratos crueles, inhumados y degradantes en supuestos de violación, en relación con situaciones de aborto eugenésico o embarazo con feto inviable (p. e. Dictamen del Comité de Derechos Humanos recaído sobre la comunicación 115372003 contra Perú): AAVV, Sentencia sobre inconstitucionalidad del Decreto Supremo n. ${ }^{\circ} 48$ del Ministerio de Salud en la parte que autoriza la distribución de la "píldora del día después" en el sistema público de salud (Tribunal Constitucional), Revista de Derecho (Valdivia) Vol. XXI - n. ${ }^{\circ} 1$ - Julio 2008, pág. 155-170. Si bien este comentario constituye una crítica al fallo que su título refiere, la idea de conflicto de derechos asociado con la vida del nasciturus es válido para el tema en tratamiento.

${ }^{52}$ Serna P. y Toller F., óp. cit., pág. 29. 
${ }^{53}$ Nogueira H. Aspectos de una Teoría de los Derechos Fundamentales: La Delimitación,Regulación, Garantías y Limitaciones de los Derechos Fundamentales. Revista Ius et Praxis. 2005; 11(2): 15-64, 2005.

${ }^{54}$ Hoyos I.M. La Corte Constitucional: entre la ley de la gradualidad y la gradualidad de la ley. A propósito del fallo sobre el aborto, Dikaion-Lo Justo, Universidad de la Sabana, Colombia en Año 20 n. ${ }^{\circ} 15$, pág. 53-70.

${ }^{55}$ Los padres potenciales tienen la obligación de tomar una decisión sobre sus descendientespotenciales. En este caso, las opciones morales son o bien rechazar los deberes parentales y aceptar la responsabilidad del aborto, o bien aceptar y cumplir esos deberes.

Comprender la aceptación de la responsabilidad parental como fuente del derecho a la vida proporciona respuestasdefinitivas a las cuestiones relacionadas con la reproducción: Rosamond Rhodes, Reproducción,aborto y derechos en Thomasma D., Thomasine K., De la Vida a la Muerte. Ciencia y Bioética (Madrid, Cambridge University Press, $1^{a}$ Edición española, 1999) pág. 82.

${ }^{56}$ Nogueira H. Pautas para Superar las Tensiones entre los Derechos a la Libertad de Opinióne Información y los Derechos a la Honra y la Vida Privada, Revista de Derecho (Valdivia), Vol. XVII, diciembre 2004, pág. 139-16.

${ }^{57}$ Al efecto, cf. Figueroa R. Concepto de persona, titularidad del derecho a la vida y aborto. Rev. Derecho (Valdivia), dic. 2007, vol. 20, David C. n. ${ }^{\circ}$ 2, pág. 95-130.

${ }^{58}$ Tribunal Constitucional, 24 de febrero de 1987. Revista de Derecho y Jurisprudencia y Gaceta de los Tribunales, tomo 84 , sección $6^{\circ}$, pág. 4 , rol n. ${ }^{\circ} 43$, considerandos 20 y 21 . Publicado en el Diario Oficial el 7 de marzo de 1987.

${ }^{59}$ Escárate K., Casanova M., Luzio W. Conflicto entre garantías constitucionales para la conservación del suelo: una revisión crítica a la legislación chilena, R.C. Suelo Nutr. Veg. 5(2) $2005(1-8)$.

${ }^{60}$ En palabras del autor Jiménez de Asúa,"La legítima defensa es repulsa de la agresión ilegítima, actual o inminente, por el atacado o tercera persona, contra el agresor, sin traspasar la necesidad de la defensa y dentro de la racional proporción de los medios empleados para impedirla o repelerla", vid. Carlos Alberto Bellatti, Causas de Justificación de la Legítima Defensa,http://noticias.juridicas.com/articulos/55-Derecho\%20Penal/200305-

24551422410341411.html, sitio consultado en julio de 2009.

${ }^{61}$ Interrupción del embarazo: Se define como la terminación del embarazo sin esperar el inicio espontáneo del trabajo de parto o aborto. Para realizar la interrupción del embarazo se utilizan diversas técnicas médico-quirúrgicas que varían según la edad gestacional, viabilidad y vitalidad fetal, cicatrices uterinas y condiciones cervicales. Más importante que el método elegido es, sin embargo, que la decisión de interrupción esté bien fundamentada. Para ello deben responderse tres interrogantes básicas:/1. ¿Por qué interrumpir? El por qué interrumpir estácondicionado por patologías médicas y obstétricas que determinan morbimortalidad materna o que establecen un 
ambiente intrauterino hostil que pone en peligro el bienestar fetal./ 2. ¿Cuándo interrumpir? El momento de la interrupción se debe elegir considerando otros elementos: grado de compromiso materno-fetal, edad gestacional y peso del feto, madurez funcional (bioquímica)del pulmón fetal, calidad de la Unidad Neonatal. En muchas ocasiones esta decisión debe ser tomada de urgencia, sin considerar la viabilidad fetal sino pensando sólo en la salud de la madre.Afortunadamente esta situación es poco frecuente. La metrorragia masiva, el hígado graso agudo,y la sepsis ovular son patologías que ejemplifican esa situación/n. ${ }^{\circ}$ 3. ¿Cómo interrumpir? El último punto de este algoritmo es crítico para asegurar el buen resultado materno y perinatal. Enmuchas ocasiones, elegir equivocadamente la vía de parto puede impedir las ventajas esperadas con la interrupción de un embarazo. Es necesario considerar: presentación fetal, bienestar fetal, estimación de peso fetal, grado de madurez cervical (modificaciones cervicales). Es el clínico quien debe juzgar adecuadamente toda la información de que dispone para decidir la interrupción de la gestación antes del término. Los objetivos finales son obtener un recién nacido en las mejores condiciones posibles, evitando la asfixia y el traumatismo perinatal, y, en ausencia de viabilidad fetal, salvaguardando la salud de la madre.

${ }^{62}$ Besio M., Chomalí F., Neira J., Vivanco, Á. Aborto terapéutico. Consideracionesmédicas, éticas, jurídicas y del magisterio de la Iglesia Católica (Santiago, Pontificia Universidad Católica de Chile, 2009) pág. 28-29.

${ }^{63}$ Miranda A. El principio del doble efecto y su relevancia en el razonamiento jurídico. Revista Chilena de Derecho. vol. 35 n. ${ }^{\circ}$ 3, pág. $485-519$ [2008].

${ }^{64}$ Ídem. Cf. John Finnis: Intention and Side Effects. En: R.-G- Frey y C.W. Morris (edits.),Liability and Responsibility: Essays in Law and Morals (Cambridge, Cambridge University Press) pág. 32-64.

${ }^{65} \mathrm{Al}$ efecto, la particular referencia a los casos de anencefalia para justificar un aborto terapéutico, se sugiere ver Mariano G. Morelli: Derechos humanos y argumentación en el caso de la anencefalia. Consideraciones filosófico-jurídicas con referencia a un caso judicial en www.cartapacio.edu.ar/ojs/index.php/byb/article/view/259/167, sitio consultado en julio de2009. Cf. además Dra. Alicia I. Losoviz y Lic. Graciela Faiman: Algunas consideraciones sobre Anencefalia: riesgo biológico versus dolor psíquico, VIII Jornadas Argentinas y Latinoamericanasde Bioética, Bioética, Vulnerabilidad y Educación. Mar del Plata, 6 al 8 de noviembre de 2003, en (http://www.bioeticaclinica.com.ar), sitio consultado en julio de 2009.

${ }^{66} \mathrm{~V}$-g. casos de México y de Colomb. 